Dikumpulkan : 28 Februari 2017

Direvisi : 22 Maret 2017

Diterima : 25 Maret 2017

\title{
Hidangan Buffet di Regular Event "Ramayana Night Market" Hotel Hyatt Regency Yogyakarta
}

\author{
HANDAYANI RAHAYUNINGSIH, BRAMANTI ADITYA \\ Diploma Kepariwisataan, Sekolah Vokasi, Universitas Gadjah Mada \\ handayani.rahayuningsih@ugm.ac.id; bramantiaditya@gmail.com
}

\begin{abstract}
Hyatt Regency Yogyakarta has strategies to increase the number of visitors to the hotel. One of the strategies made by Hyatt Regency Yogyakarta regular event "Ramayana Night Market" which is held every Saturday night. The purposes of this research are to know the buffet menu and the layout of buffet in regular event "Ramayana Night Market" at Kemangi Bistro Hyatt Regency Yogyakarta. This research used observation, interview, and documentation techniques to collect the data. The results showed that the menu in regular event "Ramayana Night Market" are presented on the long table buffet and ranged from appetizer, main course, and dessert. Regular event "Ramayana Night Market" serve traditional food as concept. The layout of the buffet at regular event "Ramayana Night Market" is made to grouping the menu based on the type (appetizer, main course, and dessert) to make it easy for the customers to take the food from the buffet.
\end{abstract}

Keywords:

Hyatt Regency Yogyakarta, Ramayana, Buffet 


\section{Pendahuluan}

Yogyakarta merupakan salah satu tujuan wisata utama di Indonesia. Beberapa tahun terakhir ini untuk mendukung kegiatan wisata yang ada, terjadi pertumbuhan hotel yang sangat pesat di Yogyakarta, baik hotel non bintang maupun hotel berbintang. Pertumbuhan hotel yang pesat tersebut mendorong persaingan yang ketat dalam industri hotel. Hotel-hotel yang ada saling berlomba untuk menarik konsumen dengan menawarkan berbagai promo seperti diskon untuk kamar dan penyelenggaraan acara khusus untuk menarik konsumen makan di restaurant hotel, sebagai contoh adalah promo all you can eat.

Selain menyediakan berbagai fasilitas yang menarik bagi wisatawan seperti Gym, Health Club, Swimming Pool, Salon and Spa, dan reastaurant, Hyatt Regency Yogyakarta yang pernah menjadi hotel terbaik kedua dari beberapa hotel Hyatt di dunia ini juga menyelenggarakan berbagai Regular Event seperti Merapi Barbeque, Ramayana Night Market, dan Sunday Brunch.

Ramayana Night Market dianggap paling menarik dari berbagai Regular Event yang ada, karena selain diadakan pada hari Sabtu tepatnya Malam Minggu, semua hidangan dari appetizer hingga dessert yang dihidangkan merupakan makanan Indonesia. Selain itu, menu yang ada disajikan dalam sistem buffet. Daya tarik utama dari Ramayana Night Market yaitu adanya pertunjukan Ramayana Ballet.

Meskipun menu yang ditawarkan bisa dibilang lengkap, ada appetizer, main course, hingga dessert, jenis makanan yang ditawarkan terbatas (menu di setiap event selalu sama). Keterbatasan tersebut bisa menimbulkan rasa bosan bagi repeater customer. Untuk itu, penulis tertarik untuk membahas mengenai "Hidangan Buffet di Event "Ramayana Night Market" Hotel Hyatt Regency Yogyakarta”.

Penelitian ini bertujuan untuk (1) Mengetahui menu buffet di regular event "Ramayana Night Market" di Kemangi Bistro Hyatt Regency Yogyakarta, (2) Mengetahui tata letak buffet di regular event "Ramayana Night Market" di Kemangi Bistro Hyatt Regency Yogyakarta.

Beberapa penelitian sebelumnya sudah ada yang dilakukan di Hyatt Regency Yogyakarta di Kemangi Bistro (Rahmaputri: 2015; Suryawardani: 2015; Etika: 2016). Penelitian tentang hidangan buffet juga sudah pernah dilakukan oleh Setiawan (2014) dan Primastuti (2016).

Penelitian yang dilakukan Rahmaputri (2015) di Hyatt Regency Yogyakarta menganalisa berbagai macam menu breakfast dan ala carte, perbedaan antara menu breakfast dan ala carte, serta mencari tahu menu khusus yang disajikan dalam event yang diadakan di Restoran Hyatt Regency Yogyakarta. Teknik yang digunakan untuk mengumpulkan data yaitu observasi dan wawancara. Hasil penelitian menunjukkan bahwa Hyatt Regency Yogyakarta memiliki dua jenis macam menu di breakfast dan ala carte yaitu western menu dan local menu. Perbedaan menu breakfast dan ala carte terletak pada table set up, service, dan menu yang ditawarkan. Selain itu, hasil penelitian juga menunjukkan adanya menu khusus yang dihidangkan dalam event khusus di Kemangi Bistro.

Penelitian terdahulu dengan fokus hidangan buffet yang dilakukan oleh Setiawan (2014) berlokasi di Sejahtera Family Hotel dan Apartment Yogayakarta. Penelitian ini bertujuan untuk mengetahui pembagian tugas Food and Beverage 
Department dalam melaksanakan menu buffet, permasalahan dan solusi ketika menerapkan menu buffet, serta koordinasi seluruh departemen dalam menerima kunjungan group. Hasil penelitian menunjukkan bahwa tugas dan tanggung jawab Food and Beverage Department dalam menerapkan menu buffet ada empat gelombang, yaitu morning shift, afternoon shift, night shift, dan kembali lagi ke morning shift. Selain melakukan pembagian shift, Food and Beverage Department juga membuat paket menu buffet. Ketika menerapkan menu buffet, Food and Beverage Department menemukan beberapa kendala, yaitu kekuarangan jumlah pax, penanganan permintaan dan komplain, spoilage and breakage, peralatan masak kurang memadai, kekurangan jumlah sumber daya manusia, dan berbagai masalah teknis. Sementara itu, koordinasi Food and Beverage Department dan departemen lain yang terkait dengan penerimaan tamu dalam bentuk rombongan dibentuk oleh Sales and Marketing Department yang dikemas di dalam inter office memo.

Berdasarkan berbagai penelitian yang telah dilakukan di Hyatt Regency Yogyakarta maupun penelitian yang berfokus pada hidangan buffet, belum ada penelitian yang membahasa tentang hidangan buffet di Hyatt regency Yogyakarta. Untuk itu, penelitian ini merupakan penelitian baru dan belum pernah diteliti sebelumnya.

Menurut Sulastiyono (2011: 5), hotel adalah suatu perusahaan yang dikelola oleh pemiliknya dengan menyediakan pelayanan makanan, minuman dan fasilitas kamar untuk tidur kepada orang-orang yang melakukan perjalanan dan mampu membayar dengan jumlah yang wajar sesuai dengan pelayanan yang diterima tanpa adanya perjanjian khusus. Kamar, makanan dan minuman, dan fasilitas lainnya yang disediakan hotel dikelola secara professional demi mendapatkan keuntungan (Rumekso: 2002). Maka dari itu, setiap manajemen hotel harus bisa memberikan pelayanan dan kepuasan terhadap konsumennya untuk mendapatkan profit dan menjaga kepuasan pelanggan.

Sebuah hotel memiliki bagian khusus yang mengurus dan bertanggung jawab terhadap kebutuhan pelayanan makan dan minum serta kebutuhan lain yang terkait tamu yang tinggal dan tamu yang tidak tinggal di hotel yaitu Food and Beverage Department (Sukresno dan Pendit, 1996:4). Sementara itu, di Food and Beverage Department, ada dua bagian yang saling bekerjasama, yaitu (1) Food and Beverage bagian depan (Front Service) yang terdiri dari restaurant, bar, lounge, banquet dan room service, (2) Food and Beverage bagian belakang (Back Service) yang terdiri dari kitchen dan stewarding,

Soekresno dan Pendit (1996:5) lebih lanjut mengemukakan tujuan Food and Beverage Department, yaitu (1) Menjual makanan dan minuman sebanyakbanyaknya dengan harga yang sesuai, (2) Memberikan pelayanan sebaik-baiknya kepada tamu sehingga tamu merasa puas, (3) Mendapatkan keuntungan sebesarbesarnya.

Sebuah restaurant yang merupakan bagian dari Food and Beverage Department, terdapat dua jenis penyajian makanan, yaitu ala carte dan buffet. Menurut Soekresno dan Pendit (1996: 28), buffet service adalah sistem penyajian makanan dimana tamu mengambil sendiri hidangan yang telah disediakan di counter (meja) dan sudah ditata dengan rapih dan menarik. Setiap hotel memiliki jenis buffet masing- 
masing, dan tidak selalu sama, karena setiap hotel mempunyai dekorasi ruangan yang berbeda. Berikut merupakan jenisjenis buffet menurut Soekresno dan Pendit (1996: 28): (1) A continual basis (tidak ada pilihan lain selain buffet), (2) A special occasion basis (buffet diadakan pada acara tertenju saja seperti lunch/dinner buffet, Sunday buffet, barbeque buffet), (3) A combination of table service dan buffet style (tidak semua makanan tersedia di meja buffet. Misalnya soup appetizer di meja buffet dan dessert di meja buffet, sedangkan main course dilayani khusus oleh pramusaji).

Sementara itu, untuk bentuk buffet, Soekresno dan Pendit (1996: 28) menyebutkan ada dua bentuk buffet, yaitu straight line shape dan scramble system. Straight line shape adalah bentuk buffet dimana terdapat satu meja memanjang dengan hidangan lengkap, mulai dari appetizer, soup, main course, dan dessert. Sedangkan buffet scramble system yaitu sistem buffet dimana terdapat beberapa meja dan diletakkan memencar, setiap meja atau stall hanya terdapat satu makanan saja.

Soekresno dan Pendit (1996: 28) lebih lanjut menjelaskan beberapa hal yang harus diperhatikan dalam menangani buffet, yaitu (1) Konsistensi dalam pelayanan yang harus tetap dijaga agar buffet tetap penuh/terisi, (2) Peralatan yang digunakan harus sesuai dengan makanan yang disajikan, (3) Mudah untuk clear-up, (4) Sanitasi dan hygiene buffet tetap terjaga, (5) Selalu menjaga makanan yang harus dimakan panas tetap panas \pm $60^{\circ} \mathrm{C}$, sedangkan makanan dingin harus tetap dingin pada suhu $7^{\circ} \mathrm{C}$, (6) Dekorasi buffet yang baik, rapih, dan menarik.

Komponen utama yang perlu diperhatikan dalam industri kuliner terutama dalam hal buffet service yaitu pelayanan. Kualitas pelayanan merupakan totalitas dari bentuk karakteristik barang dan jasa yang menunjukkan kemampuannya untuk memuaskan kebutuhan pelanggan, baik yang nampak jelas maupun yang tersembunyi (Kotler, 2000: 25). Bagi perusahaan yang bergerak di sektor jasa, pemberian pelayanan yang berkualitas pada pelanggan merupakan hal mutlak yang harus dilakukan apabila perusahaan ingin mencapai keberhasilan. Setiap hotel tentunya akan memberikan pelayanan yang baik demi mendapatkan feedback yang mereka harapkan. Pelayanan yang diberikan akan mencerminkan citra hotel tersebut.

\section{Metode}

Peneliti memerlukan beberapa data untuk mencapai tujuan penelitian,. Data yang dibutuhkan diambil dengan teknik observasi, wawancara, dan dokumentasi. Observasi dilakukan untuk mengambil data berupa menu apa saja yang menu dan tata letak buffet di regular event "Ramayana Night Market". Penulis melakukan wawancara dengan pihak yang terkait langsung dengan hidangan buffet di regular event "Ramayana Night Market". Wawancara dilakukan untuk mengetahui alasan penerapan tata letak buffet di regular event "Ramayana Night Market". Teknik dokumentasi dilakukan untuk mendokumentasikan menu dan tata letak buffet di regular event "Ramayana Night Market". Data yang terkumpul dianalisis secara deskriptif kualitatif.

\section{Hasil dan Pembahasan}




\section{Menu Buffet pada Reguler Event Night Market Kemangi Bistro Hyatt Regency Yoyakarta}

Setiap hari Sabtu pukul 19.00 WIB sampai pukul 22.00 WIB, poolside Kemangi Bistro ini digunakan untuk event Ramayana Night Market, dimana tamu dapat menyaksikan pertunjukan Ramayana Ballet sembari menyantap makan malam yang dikonsep secara tradisional yaitu seperti makan di angkringan. Pertunjukan tersebut bertujuan agar para wisatawan tidak perlu jauh-jauh ke Candi Prambanan jika ingin melihat sendratari Ramayana. Tamu sudah bisa menikmati makanan tradisional Indonesia dan Sendratari Ramayana hanya dengan $\operatorname{Rp}$ 165.000,- (belum termasuk pajak dan tax service),. Konsep ini tentu menjadi sesuatu yang unik dan menarik bagi tamu, khususnya tamu dari luar negeri.

Hyatt Regency Yoyakarta pada
Event Night Market Kemangi Bistro
menerapkan menu hidangan untuk
konsumen yaitu dengan cara pelayanan buffet. Pelayanan buffet adalah pelayanan di restoran dimana hidangan sudah disajikan secara lengkap di atas meja buffet yang berukuran panjang mulai dari appetizer, main course, dessert dan mempersilahkan tamu untuk mengambil makanan sendiri dengan bebas. Makanan yang memang seharusnya disajikan panas, dihidangkan rapi di atas serving dish yang dibawahnya terdapat pemanas atau sterno. Sementara untuk makanan yang disajikan dingin seperti salad dan buah segar, dihidangkan rapi diatas dish. Harga untuk menu buffet sudah dipastikan oleh manajemen hotel dan dengan harga yang sudah ada tamu dapat menikmati semua menu dengan bebas (all you can eat). Semua peralatan makan seperti dinner plate, soup bowl, dessert plate, dessert fork sudah tersedia di buffet, untuk dinner fork dan dinner spoon tersedia di atas meja makan tamu.

Event Night Market Kemangi Bistro Hyatt Regency Yoyakarta dilaksanakan rutin pada setiap malam Minggu mulai dari jam 19.00-22.00 WIB. Acara tersebut menyediakan beberapa menu buffet yang yaitu appetizer, main course, dan dessert. Menu-menu yang selalu disediakan di setiap penyelenggaraan regular event "Ramayana Night Market" antara lain:

\section{a. Appetizer}

Appetizer yang disajikan pada regular event "Ramayan Night Market" yaitu Pecel Solo. Pecel Solo merupakan makanan khas Solo. Makanan ini menjadi salah satu menu favorit di Reguler Event "Ramayana Night Market" Kemangi Bistro Hyatt Regency Yogyakarta karena acara ini mengangkat makanan khas dari daerah. Pecel Solo terdiri dari beberapa sayuran rebus antara lain seperti sayur kangkung, sayur kacang panjang dan kubis. Semua sayuran tersebut direbus dan untuk menyajikannya dengan saus kacang dan kerupuk. Makanan ini disajikan dingin dan dihidangkan rapih di atas meja. Bagi tamu yang menginginkan makanan ini bisa langsung mengambil sendiri (self service).

\section{b. Main Course}

Ada berbagai main course yang disajikan pada Reguler Event "Ramayana Night Market" yaitu: bebaqaran, tengkleng kambing, kambing guling, martabak gurih, nasi goreng kampong, mie goreng dan mie ghodog Djawa, dan gegorengan.

\section{Bebaqaran}

Bebaqaran merupakan proses pengolahan makanan makanan dengan cara dibakar. Macam-macam makanan 
yang disediakan di stand Bebaqaran di Reguler Event Night Market Kemangi Bistro Hyatt Regency Yogyakarta yaitu terdiri dari daging rib eye, sosis sapi, ikan kakap, sate madura, ayam bakar kecap, sate udang madu, dan sate lilit. Makanan bebaqaran ini disajikan dengan beberapa macam bumbu yaitu barbeque sauce, sambal terasi, sambal tomat, sambal matah, sambal tempe, sambal bawang dan sambal cabai hijau, tamu bisa memilih sambal sesuai yang tamu inginkan. Jika tamu menginginkan makanan Bebaqaran bisa memesan terlebih dahulu kemudian pesanan tersebut akan di proses untuk dibakar dan hingga siap disajikan.

\section{Tengkleng Kambing}

Tengkleng kambing merupakan masakan yang berasal dari Solo, makanan sejenis sup dengan bahan utama daging, jeroan dan tulang kambing. Makanan ini disajikan hangat dengan kuah santan kental yang selalu dipanaskan. Penyajian tengkleng kambing ini ditempatkan di mangkuk ditambah dengan bawang bombay, seledri, ditaburi dengan bawang goreng dan irisan cabe rawit atau sambal yang bisa ditambahkan sesuai selera. Tengkleng kambing ini juga dapat disajikan dengan nasi putih.

\section{Kambing Guling}

Kambing guling merupakan salah satu masakan yang bercita rasa khas timur tengah. Makanan ini berbahan dasar kambing yang diolah dengan cara dipanggang. Pemanggangan Kambing Guling tidak dipotong-potong melainkan dibakar utuh dan hanya dihilangkan bulu diseluruh bagian tubuh. Makanan ini disajikan dengan sambal kecap, acar, dan lontong.

\section{Martabak Gurih}

Martabak gurih merupakan martabak telur atau martabak asin yang terbuat dari adonan tepung dan campuran telur dan daging. Makanan ini disajikan bersama saus martabak dengan acar ketimun dan wortel.

\section{Nasi Goreng Kampung}

Nasi goreng adalah sebuah makanan berupa nasi yang digoreng dan biasanya diberi bumbu berupa bawang putih, bawang merah, dan bumbu, kecap. Bahan lain yang dipakai dalam pembuatan yaitu telur dan ayam. Perbedaan nasi goreng kampung dengan nasi goreng biasa, nasi goreng kampung memiliki khas sendiri dengan memakai jenis ayam kampung. Nasi goreng ini dilengkapi dengan krupuk untuk menambah ciri khas sebagai makanan Indonesia.

\section{Mie Goreng dan Mie Ghodog Djawa}

Mie Goreng Djawa dan Mie Godhog Djawa merupakan mie yang dimasak dengan bumbu khas masakan jawa dan diberi suwiran daging ayam kampung dan telur bebek ke dalam masakan. Pengunjung dapat memesan Mie Goreng dan Mie Godhog Djawa sesuai selera mereka. Peralatan yang membuat Mie Goreng Djawa atau Mie Godhog Djawa terasa lebih istimewa yaitu Anglo. Mie Goreng Djawa atau Mie Godhog Djawa ini dimasak diatas Anglo dan menggunakan arang sebagai bahan bakar.

\section{Gegorengan}

Gorengan yang disediakan antara lain lumpia, tempe mendoan, dan tahu sumedang. Gorengan ini dimasak sesuai pesanan, jika pengunjung menginginkan dengan sajian gorengan hangat akan dibuatkan gorengan yang hangat lalu 
diantarkan ke meja tamu yang memesan oleh tim food and beverage product.

\section{Dessert}

Dessert yang disediakan dalam regular event "Ramayana Night Market" yaitu serabi, jajanan pasar, dagangan kopi cantik (dakocan), dan buah.

\section{Serabi}

Serabi terbuat dari santan kelapa dan tepung beras. Serabi ini memiliki rasa yang gurih dan sedap. Pada regular event "Ramayana Night Market" para pengunjung dapat memilih varian rasa seperti keju, coklat, susu dan pengunjung dapat meminta mix varian rasa sesuai selera. Biasanya serabi banyak yang memesan karena memiliki varian rasa yang berbeda-beda menjadikan khas tersendiri. Tamu bisa meminta staff untuk membuatkan serabi sesuai dengan rasa yang diinginkan. Serabi yang disajikan masih hangat karena baru selesai dimasak dan sesuai dengan rasa dipesan. Namun, bagi tamu yang tidak sabar ingin menikmati serabi dan tidak ingin mengantri, tamu bisa langsung mengambil serabi yang telah dihidangkan dengan variasi rasa yang pastinya terbatas.

\section{Jajanan pasar}

Stand jajanan pasar ini pengunjung dapat menikmati berbagai macam jajanan pasar. Jajanan pasar yang disajikan antara lain kue mata kebo, klepon, nagasari, jentik manis dan kue talam. Khusus untuk jajanan pasar ini, pihak hotel tidak membuat sendiri tetapi membeli dari luar sehingga staff dapur Hyatt Regency Yogyakarta tidak dapat mengontrol cita rasa dan kualitas jajanan pasar. Maka dari itu, sebaiknya semua makanan termasuk jajanan pasar dibuat langsung oleh staff dapur Hyatt Regency Yogyakarta agar kualitas makanan dapat terjaga.

\section{Dagangan Kopi Cantik (Dakocan)}

Dakocan atau Dagangan Kopi Cantik ini menyediakan kopi dan teh panas untuk para pengunjung. Selain kopi dan teh panas, pengunjung juga bisa mendapatkan wedang ronde yang merupakan minuman tradisional. Staf akan meracik minuman sesuai dengan pesanan pengunjung.

\section{Buah}

Menu untuk pencuci mulut di acara Regular Event "Ramayana Night Market" disediakan bermacam-macam buah-buhan. Buah-buahan ini antara lain ada apel, jeruk, salak, melon, dan semangka. Pengunjung yang menginginkan buah-buahan tersebut bisa langsung mengambil di stand buah segar. Sementara untuk pengunjung yang menginginkan buahnya untuk dikupas bisa meminta tolong kepada staf untuk dikupas dan dipotongkan.

Menu yang ditawarkan dalam Reguler Event "Ramayana Night Market" terbilang cukup lengkap, disajikan appetizer, main course, dan dessert yang keseluruhan menu yang dihidangkan merupakan makanan tradisional Indonesia. Meskipun terbilang lengkap, tetapi makanan yang dihidangkan pada setiap acara selalu sama, tidak ada perubahan menu. Monotonnya menu tersebut sangat disayangkan karena tidak terdapat variasi menu yang bisa dinikmati konsumen yang telah berkunjung sebelumnya. Variasi menu ini perlu diperhatikan karena salah satu indikator kepuasan yaitu adanya kunjungan kembali. Jika konsumen yang berkunjung kembali bosan dengan menu yang disajikan karena hanya itu saja dan tidak pernah diganti, konsumen akan enggan untuk berkunjung kembali. Oleh 
karena itu, menu yang disediakan sebaiknya lebih bervariasi.

Tata letak Buffet pada Reguler Event "Ramayana Night Market" Kemangi Bistro Hyatt Regency Yoyakarta

Tata letak buffet sangat penting pada reguler event "Ramayana Night Market" demi memudahkan pengunjung untuk menikmati hidangan. Berikut adalah tata letak buffet pada regular event "Ramayana Night Market":

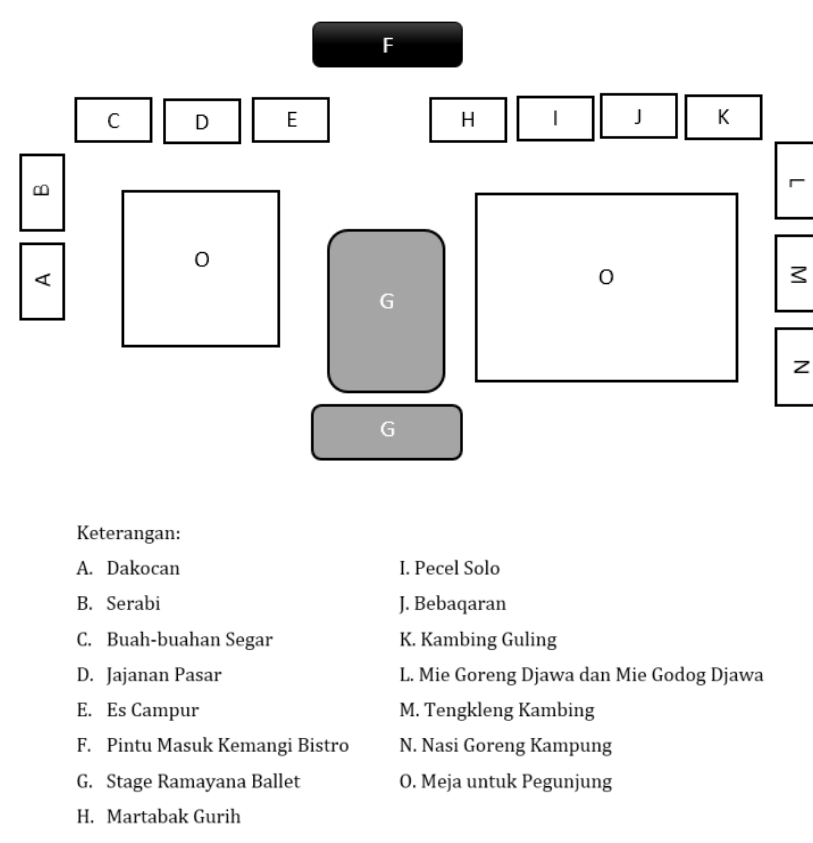

Gambar 1. Layout Buffet pada Reguler Event "Ramayana Night Market" Kemangi Bistro Hyatt Regency Yoyakarta

Sumber: Dokumentasi Peneliti

Tata letak buffet pada regular event "Ramayana Night Market" Kemangi Bistro Hyatt menggunakan scramble system. Beberapa meja atau stall ditata secara terpisah (memencar) di dalam regular event "Ramayana Night Market" Kemangi Bistro Hyatt. Setiap meja atau stall hanya menyediakan satu jenis makanan, baik itu makanan berupa appetizer, main course, maupun dessert.

Saat tamu datang untuk menghadiri regular event "Ramayana Night Market", tamu langsung diarahkan ke area poolside dari Kemangi Bistro dan tamu langsung diarahkan ke meja yang tamu inginkan. Staff akan memberikan menu minuman yang ada kepada tamu. Jika tamu memesan minuman tambahan maka pengunjung harus membayar minuman tersebut karena minuman itu tidak termasuk di buffet menu.

Saat tamu datang ke area poolside di sebelah kiri pintu Kemangi Bistro, tamu dapat mengambil makanan appetizer dan main course. Appetizer yang dihidangkan yaitu Pecel Solo. Main Course yang dihidangkan dalam event yaitu Martabak Gurih, Bebaqaran, Kambing Guling, Mie Goreng Djawa, Mie Godhok Jawa, Tengkleng Kambing dan Nasi Goreng Kampung. Sementara di sisi sebelah kanan, tamu dapat mengambil berbagai macam dessert yang telah disediakan seperti es campur, jajanan pasar, buah-buahan, serabi dan dakocan.

Tata letak buffet pada Regular Event "Ramayana Night Market" ini diletakan dipinggir area poolside. Diletakan dipinggir karena supaya pengunjung tidak mengganggu pengunjung lain yang sedang menyaksikan pertunjukan Ramayana Ballet. Peletakan buffet dipinggir area juga mempermudahkan pengunjung untuk memilih makanan yang diinginkan.

Staff Kemangi Bistro dalam menata hidangan, melakukan pengelompokkan berdasarkan jenis makanan, yaitu appetizer, main course dan dessert. Tata letak hidangan dilakukan untuk mempermudah pengunjung dalam memilih hidangan. Hidangan appetizer dan main course terletak disebelah kiri pintu masuk 
Kemangi Bistro sedangkan hidangan dessert terletak disebelah kanan pintu Kemangi Bistro. Peletakan ini disesuaikan berdasarkan pengelompokan makanan yaitu appetizer, main course dan dessert untuk memudahkan pengunjung mengambil hidangan.

Alur peletakan buffet pada event night market sudah dikelompokkan. Pada sebelah kiri dari pintu Kemangi Bistro adalah appetizer dan main course sedangkan di sebelah kanan adalah dessert.

Selain mengatur tata letak hidangan, meja tempat makan tamu juga diatur. Meja disusun di sisi kanan dan kiri dari stage untuk pertunjukan Ramayana dan dikelilingi oleh stall makanan. Tujuan dari penataan meja makan pengunjung ini yaitu selain untuk mempermudah tamu dalam memilih dan mengambil makanan yang dihidangkan, juga agar tamu bisa leluasa dalam menikmati pertunjukan Sendratari Ramayana yang ditampilkan.

Staff mengatur meja dan stall dengan jarak yang berdekatan untuk mempermudah tamu dalam mengambil makanan dan jarak tidak terlalu jauh. Namun, sistem ini memiliki kekurangan yaitu pada saat ramai, tamu yang berkunjung banyak, sehingga kenyamanan tamu sedikit terganggu. Jarak yang dekat antara stall tempat makan mengakibatkan tamu yang sedang makan terganggu dengan tamu yang sedang mengambil makanan, dan begitu pula sebaiknya. Oleh karena itu, jarak antara meja makan dan stall perlu diperlebar dan diperlapang agar tamu yang sedang makan dan tamu yang sedang mengambil makanan tidak terganggu dengan tamu yang lain.

Selain itu, bentuk penyusunan stall selalu sama setiap acara, belum pernah dilakukan perubahan. Perubahan penataan perlu dicoba untuk dilakukan agar tercipta suasana baru. Selain itu, perubahan tata letak stall dapat dimanfaatkan untuk memperbaiki kekurangan dalam tata letak yang ada terutama dalam hal kenyamanan tamu yang sedang makan dan sedang mengambil makanan.

\section{Kesimpulan}

Berdasarkan pembahasan di atas, dapat disimpulkan sesuai perumusan masalah yaitu sebagai berikut:

a. Hidangan yang ada di regular event "Ramayana Night Market" disajikan secara lengkap di atas meja buffet yang berukuran panjang mulai dari appetizer, soup, main course, dessert. Menu yang dihidangkan adalah menu tradisional Indonesia.

b. Tata letak buffet pada regular event "Ramayana Night Market" stall atau meja disusun dengan scramble system, yaitu meja disusun secara terpisah dan setiap stall disediakan satu jenis makanan. Makanan ditata dan dikelompokkan berdasarkan jenis makanananya agar memudahkan para tamu untuk mengambil makanan di buffet. Selain itu, penataan stall dan makanan disusun sedimikian rupa agar tamu selain dapat menikmati makanan, juga dapat menikmati pertunjukan Sendratari Ramayana yang ditampilkan.

Berdasarkan pembahasan yang telah dilakukan, untuk meningkatkan kualitas dari Regular Event "Ramayana Night Market" terutama terkait dengan hidangan buffet, penulis merumuskan beberapa saran, yaitu:

a. Sebaiknya menu yang diberikan pada saat regular event "Ramayana Night Market" lebih bervariasi, tidak hanya itu saja, perlu diganti dengan makanan khas Indonesia lainnya agar tamu tidak 
merasa bosan dengan menu yang disajikan.

b. Agar Regular Event "Ramayana Night Market" yang diadakan oleh Hyaat Regency Yogyakarta lebih menarik dan agar pengujung yang datang lebih banyak, perlu ditambahkan hiburan lain sesudah pertunjukan Ramayana Ballet.

c. Jajanan pasar pada Regular Event "Ramayana Night Market" sebaiknya dibuat sendiri sehingga memiliki cita rasa khas Hyat Regency Yogyakarta dan kualitas makanan bisa terjaga.

d. Letak meja buffet dan meja tamu diberikan jarak yang lebih lapang agar pada saat ramai tidak menganggu kenyamanan pengunjung.

e. Tata letak buffet dibuat tatanan baru yang lebih menarik lagi agar tercipta sesuasana baru pada setiap penyelenggaraan event. Sebagai contoh, meja buffet diletakkan di samping panggung.

\section{Daftar Pustaka}

Etika, Lulut. 2016. "Peran Media Sosial Dalam Membantu Promosi Special Event di Hyatt Regency Yogyakarta Oleh Public Relation Section pada Februari-Maret 2016". Tugas Akhir. Yogyakarta: Universitas Gadjah Mada.

Kotler, P. 2000. "Manajemen Pemasaran". Jakarta: PT. Prenhallindo.

Primastuti, Hana Shofya Brian. 2016. "Perbandingan Tipe Pelayanan Buffet Service dan Cafeteria Service pada Pelayanan Makan Siang di Kantin Sekolah Terhadap Tingkat Asupan Energi dan Protein pada Siswa SMA di Kota Yogyakarta". Skripsi. Yogyakarta: Universitas Gadjah Mada.

Rahmaputri, Astrid Nuke. 2015. "Berbagai Macam Menu Breakfast dan Ala Carte yang Disajikan di Kemangi Bistro Hyatt Regency Hotel Yogyakarta". Tugas Akhir. Yogyakarta: Universitas Gadjah Mada.

Rumekso. 2002. "Housekeeping Hotel Floor Section". Yogyakarta: Andi.

Setiawan, Gabriel Indra. 2014. "Penerapan Menu Buffet Bagi Tamu Group di Sejahtera Family Hotel dan Apartment Yogyakarta". Tugas Akhir. Yogyakarta: Universitas Gadjah Mada.

Soekresno dan Pendit, S. I. 1996. "Petunjuk Praktek Pramusaji Food \& Beverage Service, Buku Panduan Sekolah Pariwisata \& Perhotelan". Jakarta: PT Gramedia Pustaka Utama.

Sulastiyono, A. 2011. "Manajemen Penyelenggaraan Hotel, Seri Manajemen Usaha Jasa, Sarana Pariwisata dan Akomodasi". Jakarta: CV. Alpabeta.

Suryawardani, Franciska Ririn. 2015. "Prosedur Pelayanan Evening Cocktail untuk Meningkatkan Kepuasan Tamu di Regency Club Lounge Hotel Hyatt Regency Yogyakarta". Tugas Akhir. Yogyakarta: Universitas Gadjah Mada. 